\title{
La impugnación de legitimidad en México. De la disolución de la XXVI Legislatura a la Soberana Convención Revolucionaria
}

\section{Contesting Legitimacy in Mexico. \\ From the Dissolution of the 26th Legislative Session to the Sovereign Revolutionary Convention}

\author{
Juan Bernardino Sánchez Aguilar \\ Universidad Nacional Autónoma de México, México \\ (D) orcid.org/0000-0001-9783-1852 \\ juanbernardino1976@gmail.com
}

Resumen: El artículo se centra en una coyuntura de la historia de México, pues entre 1913 y 1914 aconteció un giro estrepitoso a la incipiente democracia practicada durante el gobierno de Francisco I. Madero. A partir de ese momento, el golpe de Estado huertista fue combatido por diferentes grupos de revolucionarios; así que cuando estos vencieron al régimen usurpador, inició un periodo de definición política y militar nada desdeñable para el estudio de los historiadores.

Palabras clave: legitimidad; revolución; militarismo; representación; soberanía.

Abstract: This article focuses on the period between 1913 and 1914, when the incipient democracy that had emerged under Francisco I. Madero underwent a dramatic change. Thereafter, various groups of revolutionaries fought against the coup d'état by Victoriano Huerta. When they defeated the usurper's regime, a period of political and military definition that has been of enormous interest to historians. 
Key words: legitimacy; revolution; militarism; representation; sovereignty.

Fecha de recepción: 25 de julio de 2016 Fecha de aceptación: 27 de febrero de 2017

$\mathrm{P}_{\mathrm{s}}$ ierre Rosanvallon (1999) asume que los regímenes totalitarios, o las dictaduras militares, no se atreven a rechazar el sufragio universal desde que este se convirtió en piedra angular de todo sistema político; "casi siempre prefieren manipular, más que prohibir", asienta, "y si suspenden su ejercicio, se apresuran a subrayar el carácter provisional de esta medida” (p. 9). Con esa premisa es factible acercarnos a los golpes de Estado o a las insurrecciones armadas debido a que con frecuencia se inician justificando el uso de la fuerza $y$, después, prometen hacer efectivo el voto de los ciudadanos. Así que en este trabajo se abordarán los procesos de impugnación de legitimidad; entendiendo este concepto como el derrumbamiento de las instituciones políticas para instaurar otras nuevas (Levi, 1997, p. 864).

Cabe señalar que el significado unívoco de legalidad no explica por sí solo el contexto político de un gobierno, aunque este recurra a su amparo. El término legitimidad tiene un carácter doble y observa la coexistencia entre una "legitimidad derivada del reconocimiento social de un poder" y una "legitimidad como adecuación a la norma" (Rosanvallon, 2010, p. 25). Algunos autores rechazan esa "posición reduccionista que identifica la legitimidad política con la mera autojustificación del poder político" (Diego, 2003, pp. 154-155), y esto nos obliga a ser cautos cuando se abordan las discusiones teóricas sobre el sustento del poder. ${ }^{1}$

Por ejemplo, si se considera que las revoluciones provocan escenarios de "soberanía múltiple", porque dos o más bloques intentan controlar el Estado (Tilly, 1995, p. 26), es factible realizar estudios sobre las pugnas y sus consecuentes luchas armadas. Para el caso de la revolución mexicana se dice que inició con una "fuerte connotación constitucional", al oponerse a una reelección más de Porfirio Díaz y estar en contra de la "perversión" de la carta magna (Portillo, 2016, p. 196). Pero una vez iniciado el gobierno de

${ }^{1}$ Carl Schmitt (2012), por ejemplo, asentó en 1940 que "la validez formal de una ley no significa que se pueda hallar una respuesta suficiente a la cuestión de la rectitud de la decisión apelando sin más a la 'legalidad”. En ello podríamos estar de acuerdo; pero si tras esto el autor alemán indica que todo procede de la "voluntad" del "legislador", pues para él esta se considera "norma" (pp. 17 y 43), entonces vemos que el partido nazi vio reforzadas sus ideas totalitarias con las de Schmitt al iniciar la segunda guerra mundial.

\section{(이요}


Francisco I. Madero se infiere que la "ampliación de los derechos políticos y la considerable apertura de la opinión pública" provocaron "un clima inestable y destructivo" al carecer de "normas claras" para regular la competencia (Rojas, 2002, p. 108). Esta situación nos hizo reflexionar sobre lo sucedido entre la disolución de la XXVI Legislatura (octubre de 1913) y el establecimiento de la Soberana Convención Revolucionaria (octubre de 1914); sobre todo, porque durante esa etapa se acentuó el uso de la fuerza para controlar a las instituciones.

Es evidente que el derrumbe de la democracia maderista se dio a inicios de 1913 con la llamada "Decena Trágica": diez días transcurrieron del ataque al Palacio Nacional (9 de febrero) a la admisión de las renuncias de Madero y Pino Suárez por el Congreso (19 de febrero). Ante la ausencia del presidente y del vicepresidente, la titularidad del poder ejecutivo debía recaer en el encargado de Relaciones Exteriores. Sin embargo, Pedro Lascuráin sólo juró la presidencia para nombrar secretario de gobierno a Victoriano Huerta y después renunció. Esta situación le permitió al artífice del levantamiento hacerse de la más alta investidura, por lo que Josefina Mac Gregor (1986) sostiene lo improcedente en afirmar "que a Huerta no le interesara mantener su gobierno y su persona dentro de las prescripciones legales" (p. 10).

El legado institucional del apóstol de la democracia, por otro lado, se vio reflejado en el actuar de la XXVI Legislatura. Esta asamblea había sido electa mediante el voto universal y directo, ${ }^{2}$ y para entonces era el "escenario de un juego partidista que pocas ocasiones se había podido advertir en México" (Mac Gregor, 2015, p. 201). El cambio del titular de la presidencia en 1913 había modificado la relación entre los poderes ejecutivo y legislativo, sobre todo porque Madero y Pino Suárez fueron asesinados tres días después de sus renuncias. Así que nuestro análisis parte de la disolución de esta legislatura -ocho meses después de la Decena Trágica- hasta la integración de la Soberana Convención Revolucionaria.

Sobre la integración de esta última asamblea se debe advertir que no existieron comicios: esta circunstancia la sustrajo de los balances institucionales del Congreso, aunque el peso de su simbolismo no dejó de brillar después de los revisionismos. Es inobjetable, por ejemplo, que varios prota-

${ }^{2}$ Para las elecciones de junio de 1912 entró en vigor una reforma electoral que cambió la modalidad de los comicios de diputados y senadores de indirectos a directos; es decir, a partir de entonces los varones (mayores de 18 años si estaban casados y de 21 si eran solteros) votaron por sus legisladores; lo que no sucedía antes, cuando primero se designaba a los electores que sufragarían después por los integrantes del Congreso.

\section{()(1) $(3$}


gonistas del periodo criticaron a la Soberana Convención; como don Luis Cabrera (1948), para quien las convenciones de México y Aguascalientes sólo representaron "el regateo de las tendencias personalistas" (p. 85), mas, tiempo después, fue valorada su "representatividad política" por fungir como un "auténtico poder nacional" en Aguascalientes (Córdova, 1990, p. 130). Schmitt (1981) asienta que "en vías revolucionarias puede ser suprimida, no sólo la legislación constitucional y la Constitución, sino también la especie de Poder constituyente" (p. 109). ${ }^{3}$ En consecuencia, no es de extrañar que en la penúltima conmemoración de este organismo se dijera que la "legitimidad y la creación de instituciones" habían sido la "preocupación" más importante de "convencionistas y carrancistas" (Meyer, 1990, p. 137).

\section{LA DISOLUCIÓN DE LA XXVI LEGISLATURA}

Cuando el general Victoriano Huerta decretó la disolución de la XXVI Legislatura, las discrepancias entre estos dos poderes ya eran considerables. Un tema de tensión había sido la convocatoria a elecciones extraordinarias de presidente y vicepresidente, entre abril y mayo de 1913, porque las comisiones que conocían "el asunto recomendaron" posponer los comicios "para cuando se dictaminara la ley electoral respectiva". Esa actitud de la Cámara de Diputados "golpeó" seriamente la candidatura de Félix Díaz, allanándole el camino a Huerta para seguir siendo el titular del poder ejecutivo. Aunque por esos días un grupo de diputados también utilizó la tribuna para pedir su renuncia; es decir, el presidente estaba siendo acusado de ser uno de los principales "trastornadores del régimen constitucional" (Mac Gregor, 1986, pp. 14-17).

Este contexto de tensión entre poderes se agravó con la desaparición del senador Belisario Domínguez: ${ }^{4}$ el 9 de octubre de 1913 la diputación de Chiapas le solicitó al pleno que pidiese cuentas al secretario de Gobernación

${ }^{3}$ Este argumento también lo podemos seguir con el trabajo del célebre constitucionalista mexicano Felipe Tena Ramírez (1976); para él las revoluciones provocan una "modificación violenta de los fundamentos constitucionales de un Estado" (p. 73).

${ }^{4}$ Jesús Romero Flores (1998), al hacer un recuento sobre las víctimas del huertismo, enumera los asesinatos antes ocurridos de Gustavo Madero, Adolfo Bassó, Gabriel Hernández, Solón Argüello, Alfredo Campos, Juan Izabal, Juan Pedro Didapp, Alfonso Zaragoza, José Llanes, Juan González, Mariano Duque, Emilio Palomino y otros. Esto nos da una idea sobre las muertes que ya habían antecedido a la del senador Belisario Domínguez (pp. 503-507).

\section{()(1) $\$$}


sobre lo sucedido. Para ese momento ya se sabía de dos desapariciones más: las de los diputados Serapio Rendón y Adolfo Gurrión ${ }^{5}$ (quienes, después se supo, fueron asesinados); así que al día siguiente fueron aprendidos los legisladores asistentes al recinto bajo parlamentario (Mac Gregor, 2010, pp. 137 y 139). El total de diputados encarcelados fue de 83 , y cabe mencionar que entre ellos se encontraban personajes "que Huerta consideraba sus enemigos, como Rodolfo Reyes y Jorge Vera Estañol, ex secretarios de Estado de su gabinete" (Mac Gregor, 2017, p. 1355).

Al ser disuelta esta asamblea, el presidente Huerta decidió reemplazarla con la nada memorable XXVI Legislatura bis: en ella se sustituyó a los legisladores que le eran "francamente hostiles" y fueron agregados "varios hacendados, hombres de negocios, intelectuales, familiares, hijos de amigos y colaboradores" de su gobierno (Ramírez, 2005, p. 184). Este hecho lesionó aún más la poca aceptación que ya se tenía del poder ejecutivo en México. Y fue así como muchos personajes de la política se adhirieron al Plan de Guadalupe (para desconocer de esa manera a Victoriano Huerta, como jefe del ejecutivo, y a los poderes legislativo y judicial de la federación).

La postura oficial del gobierno en torno a la suspensión violenta de labores en la Cámara de Diputados la encontramos el 20 de noviembre de ese mismo año. El titular del poder ejecutivo ofreció un discurso al Congreso renovado y argumentó que en "legítima reacción defensiva y de salud pública" se había prescindido "por breve plazo de la llamada Representación Nacional" y convocado "al pueblo a los comicios para que él, como soberano, dijera la última palabra" ${ }^{6}$ La elección de esta nueva legislatura se realizó el mismo mes en que fue disuelta su antecesora (octubre de 1913). Así que la prensa -antes contraria al presidente Madero-no dudó en apoyar al general Huerta por dicha medida:

${ }^{5}$ Para el caso de las órdenes de aprehensión y asesinato del diputado Adolfo Gurrión, el menos estudiado de los legisladores desaparecidos durante el gobierno de Huerta, se debe señalar que en los telegramas del gobierno federal se insistía en que las autoridades locales -en este caso de Oaxaca- aplicaran "estrictamente la Ley" al aprehenderlo (lo que bien podía entenderse como una orden para asesinarlos). El encargado de mandar estas órdenes era el secretario de Gobernación, Aureliano Urrutia, quien por ese medio pedía hacer "sentir la mano del gobierno", así como no mostrar "vacilación alguna" para aplicar "todo el rigor de la ley”. Véase Sobre la muerte del diputado Adolfo C. Gurrión en De cómo (1978, pp. 312-315).

${ }^{6}$ Diario de los debates de la Cámara de Diputados. Segunda XXVI Legislatura (en adelante DDCD. XXVI Bis). Sesión del 20 de noviembre de 1913.

\section{()(1) $\$$}


En las graves circunstancias por que atraviesa el país, la Constitución quiere que se suspendan las garantías individuales, y se otorguen facultades extraordinarias al Primer Magistrado de la Nación. Y en lugar de seguir este camino, la Asamblea decidió tomar el opuesto; restar al Ejecutivo prestigios y poderes, haciéndolo juguete de caprichos parlamentarios, y contribuyendo así a un desorden de cosas que precipitadamente nos habría llevado, si Dios y Huerta no lo hubieran remediado, a la más completa ruina [...] ¿Era esto patriótico? [...] ¿Era esto legal? ${ }^{7}$

El Imparcial no publicó el nombre del autor de esta columna, pero probablemente fue escrita por Salvador Díaz Mirón, quien llegó a firmar otras críticas sobre la XXVI Legislatura en el mismo diario. ${ }^{8}$ El principal argumento de apoyo al régimen indica que la carta magna "quería" la suspensión de garantías individuales y el otorgamiento de facultades extraordinarias al poder ejecutivo, pudiéndose percibir con ello una aparente supremacía de la ley sobre los hombres (elemento sin duda importante para legitimar a un gobierno golpista). No obstante, en esas mismas líneas también se menciona que el país pudo haber quedado en ruinas "si Dios y Huerta no lo hubieran remediado". Esta situación nos hace reflexionar en torno a otro sentir publicado en El Independiente, sobre todo porque señalaron que Huerta no sólo había arrojado "a los mercaderes del templo" como Jesús de Nazaret (refiriéndose al cese que hizo el general de Jorge Vera Estañol y Rodolfo Reyes del gabinete y su posterior encarcelamiento), sino que el presidente había excedido la paciencia de Job al permitir que las cámaras colegisladoras se convirtieran en "casas de orates". 9

¿No eran estas demasiadas alusiones a la justicia divina? ${ }^{10}$

${ }^{7}$ Véase Luis del Toro, La cuestión legal en De cómo (1978, pp. 385-386, las cursivas son mías).

${ }^{8}$ Como ejemplo de esto podemos ver "Notas de actualidad", donde Díaz Mirón afirma que los diputados de la XXVI Legislatura eran una "impura y temible turba, que no concebía ni votaba sino barbaridades peligrosas e indignas”. De cómo (1978, p. 399).

${ }_{9}$ Véase Otro comentario periodístico, en De cómo (1978, pp. 400-401).

${ }_{10}$ Quienes han estudiado el tema de la prensa en el periodo, como Luciano Ramírez (2004), advierten que el gobierno huertista clausuró varios periódicos por el sólo hecho de "informar a sus lectores" sobre los acontecimientos de los grupos revolucionarios. No es de extrañar entonces que, ante esos ataques a la libre imprenta, los diarios catalogados como porfiristas y enemigos del presidente Madero hicieran apologías sobre el general Victoriano Huerta. Ramírez Hurtado encuentra que, sólo hasta la renuncia del pretoriano, los periódicos publicaron fotografías de los constitucionalistas; y fue hasta julio de 1914 cuando comenzaron a detallar los crímenes perpetrados durante el gobierno golpista (p. 177).

\section{()(1) $\$$}


Otro de los argumentos utilizados para justificar la disolución de la XXVI Legislatura se tomó de las gestiones realizadas por el presidente Benito Juárez; es decir, para Querido Moheno, "el patricio más ilustre de este país" había gobernado "casi toda su vida como un dictador, bajo el régimen constante de facultades extraordinarias, que prácticamente reducen a cero el poder de las cámaras". Este legislador antimaderista indicó que la XXVI Legislatura no había emanado "propiamente del sufragio popular, sino del sufragio de caciques locales". Y al convertirse en secretario de Relaciones de Huerta, Moheno sostuvo que "la actitud del gobierno en el fondo" era "eminentemente democrática, puesto que al disolver las cámaras" convocaba "en brevísimo tiempo al pueblo mexicano" a elecciones. ${ }^{11}$

¿Cómo integraron la Segunda XXVI Legislatura de la Cámara de Diputados? ¿Se llevaron a cabo todos los procedimientos establecidos para legitimarla?

Al revisar el registro de participaciones en la primera junta preparatoria de esta legislatura observé poco interés por dar seguimiento al orden legal de sus actos. Un presunto legislador de apellido Zúñiga llamó la atención de la asamblea para que, "ajustándose a la Ley", eligieran a la mesa directiva; pero los nuevos representantes no mostraron disposición para aplicar el reglamento interior del Congreso. Ante esa negativa, el inconforme apuntó:

El nombramiento [de la Mesa] es nulo de plena nulidad, puesto que se ha hecho contrariando la ley expresa, que dice que se ha de hacer a mayoría de votos y en escrutinio secreto. ¿Por qué vamos a violar la ley? [...] (una voz: ¡No es ley!) Es ley, señores, es el Reglamento de la Cámara, es una ley expedida por la Cámara de Senadores y mandada publicar por el presidente; [...] De manera que yo pido que no faltemos a la ley. ${ }^{12}$

Salvador Díaz Mirón -ahora como diputado- refutó los señalamientos de Zúñiga; si el recinto bajo parlamentario se encontraba en "condiciones anormales", señaló el veracruzano, no debía exigirse la "estricta regularidad en el presente caso". Por ello se formaron de inmediato las comisiones revisoras de credenciales, que fungían como los únicos organismos encargados de verificar la "legitimidad del nombramiento de todos los miembros de la

${ }^{11}$ Declaraciones del jefe del gabinete. De cómo (1978, pp. 387-388).

${ }^{12}$ DDCD. XXVI Bis, sesión del 15 de noviembre de 1913. 
Cámara”. ${ }^{13} \mathrm{Y}$ al día siguiente los reclamos de Zúñiga fueron considerados "una causa baladí" por el periódico El Imparcial. ${ }^{14}$

Cabe mencionar que días antes de estos debates ya se había publicado un problema de mayor envergadura en El Diario. Después de las elecciones de ese 26 de octubre, las credenciales de diputados no se recibían "aún" en la Cámara Baja:

Enterado el Oficial Mayor de la petición de los futuros señores diputados, contestaba a su vez: "la credencial de usted no la tengo aún; pero hoy he recibido 547 pliegos certificados, y entre ellos debe estar, con toda seguridad, la suya. Además, en la secretaría de la presidencia y en el Ministerio de Gobernación hay muchas credenciales, de modo que el lunes le será entregada. Mas eso no es óbice para que usted no asista a esta sesión; pase usted al salón." Y poco a poco los curules fueron ocupándose hasta sumar ciento setenta y dos el número de futuros padres de la patria. ${ }^{15}$

Después de ese notorio "retraso" en la recepción de documentos que certificaban las elecciones, y tras dos días de labores, las comisiones dictaminadoras de la Cámara encontraron "legítimos" a 203 representantes. Sólo un presunto diputado por el $16^{\circ}$ Distrito del estado de Jalisco reclamó que no fuera mencionado su triunfo en la lista de escrutinio; pero cuando la mesa directiva observó que otro personaje también traía una credencial, por ese mismo distrito, el secretario les pidió a ambos sus documentos para que la comisión rindiera su dictamen..$^{16}$ De este asunto ya no se volvió a hablar en los debates, y al día siguiente fue publicada una crónica distinta en El Diario sobre los hechos; es decir, para El Diario Independiente de la Mañana, Nicolás Barragán se había equivocado de distrito cuando reclamó y en la noticia mezclaron sus argumentos con los de su oponente Enrique Corona. ${ }^{17}$ Debo mencionar que la crónica de ese periódico se aleja mucho de lo registrado en el Diario de los Debates de la Cámara de Diputados; aunque también El Im-

${ }^{13}$ Véase Reglamento para el Gobierno Interior del Congreso General de los Estados Unidos Mexicanos en Historia (1997, p. 624).

${ }^{14}$ El Imparcial. Diario Independiente, domingo 16 de noviembre de 1913, t. xxxv, núm. 7163, p. 1.

${ }_{15}$ El Diario. Diario Independiente de la Mañana, domingo 16 de noviembre de 1913, año VIII, núm. 2049, p. 7. Las cursivas son mías.

${ }^{16}$ DDCD. XXVI Bis, sesión del 18 de noviembre de 1913.

${ }_{17}$ El Diario. Diario Independiente de la Mañana, miércoles 19 de noviembre de 1913, año VIII, núm. 2052, p. 71.

\section{()(1) $\$$}


parcial optó por publicar que los expedientes habían sido "encontrados sin irregularidades". ${ }^{18}$

¿Qué balance se hizo en su momento sobre la disolución de la Cámara de Diputados?

Uno de los críticos que vio más allá de las argumentaciones manipuladas de los periódicos fue Francisco Bulnes. Cuando explicó "el golpe de Estado en su parte jurídica" sostuvo:

En mi concepto el general Huerta no ha tenido razón al decir: "con esta Cámara ni puedo gobernar"; debió decir lo que hombres como Comonfort, don Manuel Doblado [...] y como don Benito Juárez y don Sebastián Lerdo de Tejada en 1867: "con esta Constitución no se puede gobernar". El culpable [...] del golpe de Estado, no son los jacobinos de la Cámara, fueron los jacobinos de la Constitución y los jacobinos que forman desgraciadamente la mayoría de los liberales en México. [...] Es la Constitución la que ha hecho a la Cámara omnipotente. ${ }^{19}$

De los trabajos que abordan las tensiones surgidas entre la XXVI Legislatura y el presidente Huerta, los de Josefina Mac Gregor (1986) son los que más reflexionan en torno a esta última postura; para ella, los diputados de esta asamblea "fueron más allá de lo que Emilio Rabasa llamó en sus estudios congresismo o congresionalismo", pues en opinión del constitucionalista esa "era la característica más importante y la más censurada" de "la Carta Magna de 1857". Esta historiadora advierte que los legisladores de la asamblea maderista se mostraron "preocupados por el papel que la Cámara desempeñaba en el sistema político mexicano, y siempre estuvieron dispuestos a defender las facultades que les correspondían y su carácter de poder independiente" (pp. 13-22).

La disolución de la Cámara de Diputados, sin lugar a dudas, acrecentó la crisis institucional iniciada por Victoriano Huerta con la Decena Trágica: en ambos casos se había utilizado a las fuerzas armadas para encarcelar y hasta asesinar a los representantes electos por el pueblo. Por esa razón debe revisarse lo sucedido de manera paralela con los revolucionarios, pues con la redacción del Plan de Guadalupe el gobernador de Coahuila había obtenido

${ }^{18}$ El Imparcial. Diario Independiente, miércoles 19 de noviembre de 1913, t. xxxv, núm. 7167, p. 1.

19 El golpe de Estado, en De cómo (1978, pp. 405-406).

\section{()(1) $(9$}


plenos poderes por parte de su legislatura para oponerse al gobierno golpista; y otras facciones, como la zapatista, no cejaban en su lucha contra el gobierno federal. Es por esto que resulta importante revisar las opciones propuestas sobre la representación política en el contexto revolucionario.

Por ejemplo, cuando revisamos los antecedentes de la Soberana Convención Revolucionaria observamos que fueron los zapatistas quienes plantearon, desde un inicio, "la necesidad de organizar una reunión entre los principales jefes militares revolucionarios". El objetivo buscado para dicho encuentro quedó plasmado en el Plan de Ayala, ya que en él se asentó la necesidad de integrar "una Junta de los principales jefes revolucionarios de los diferentes Estados", para nombrar "un presidente interino", y a su vez convocar "a elecciones". Es evidente que dicho organismo se encargaría de "legitimar a nivel nacional la revolución". Aunque "el procedimiento" que debían seguir para integrar esa junta no quedó claro en el documento de noviembre de 1911, como asienta Ávila (1991, pp. 21-22).

Otro de los grupos armados que también pugnó por la creación de una asamblea revolucionaria fue el villista. Cuando el régimen de Victoriano Huerta comenzó a caer ante los ataques del Ejército Constitucionalista, las divisiones del Norte y Noreste firmaron en julio de 1914 el establecimiento de una convención mediante los acuerdos de Torreón. Cabe mencionar que la redacción de ese documento se dio en gran parte por las tensiones surgidas entre Venustiano Carranza y Francisco Villa, siendo necesaria la reunión de algunos de sus representantes para "zanjar" sus dificultades. ${ }^{20} \mathrm{Y}$ por ello debemos detenernos en estos acuerdos.

El primer historiador en realizar un exhaustivo análisis sobre estas desavenencias fue Robert Quirk (1962). Él señala que Pablo González invitó a la División del Norte a reunirse en Torreón con representantes del Ejército del Noreste, aunque "Carranza negó que la comisión fuera enviada por él", dejándole claro al representante del gobierno estadunidense -Carothers- que los generales iban "por su propia iniciativa para ver si es posible restablecer la concordia”. En esa entrevista, el barón de Cuatrociénegas sostuvo que Villa se creía "indispensable para la causa constitucionalista", pero en su sentir el Centauro del Norte estaba "muy equivocado" porque "ninguna persona que" desafiara "a las autoridades constituidas" lo era (p. 41). Quirk (1962) también

${ }^{20}$ Jorge Sayeg Helú (1982, p. 81) indica que la insubordinación de Villa en la toma de Zacatecas propició que militares de ambos bandos intentaran disminuir las tensiones entre ambas figuras revolucionarias.

\section{()(1) $(9$}


señala que el Primer Jefe "no se sentía en forma alguna obligado por las decisiones que tomaran seis hombres en Torreón", porque ninguno de ellos "lo representaba a él” (p. 44). Y es que, "lo que más parecía importar a los delegados villistas" en Coahuila, de acuerdo con Amaya (1966, p. 27), era la adición de nuevos artículos al Plan de Guadalupe, sobre todo en lo concerniente a integrar una convención.

Por este tipo de situaciones Carranza había rechazado antes el envío de representantes a Estados Unidos para negociar con los huertistas. Berta Ulloa (1976) advierte que el Primer Jefe le mencionó a uno de los agentes del presidente Woodrow Wilson que una "paz momentánea" sólo habría desembocado "en otra revolución" y agregó: las "reformas que México" necesita "urgentemente" tienen que "hacerse por medio de decretos"; "si antes de realizarlas aceptaban a un presidente provisional, este tendría que someterlas al Congreso de la Unión, y con el que Huerta había constituido, sería vano cualquier intento" (p. 381). Charles Cumberland (1975, p. 145) asegura que Villa y sus consejeros desconfiaban tanto de las ambiciones políticas del Primer Jefe que, precisamente en Torreón, presentaron la propuesta de integrar una asamblea; así que con ese organismo fijarían las fechas de "las elecciones" y discutirían "el programa de Gobierno", además de poner en funciones a las autoridades que resultasen electas. ${ }^{21}$ Es evidente que con las adecuaciones de Torreón se pretendía cambiar lo escrito en el Plan de Guadalupe, ya que en dicho texto se anunciaba que sólo el presidente interino convocaría "a elecciones tan luego como se haya consolidado la paz", ${ }^{22}$ por lo que el Primer Jefe sostuvo que "un asunto de tan grande importancia" no podía ser discutido ni aprobado "por un grupo tan reducido de personas" (Quirk, 1962, p. 47).

Cabe mencionar que la intención inicial del coahuilense en el Plan de Guadalupe sólo había sido la de derrocar a Victoriano Huerta y "restablecer la legalidad maderista” (Ávila, 1991 p. 31). La historiografía clásica ha mencionado que "lo que más le desagradaba" a Carranza era el "aparente propósito de cerrarle el camino para llegar a la presidencia constitucional”, al impedirse "que los funcionarios provisionales se presentaran en las elecciones" (Quirk, 1962, p. 48); de ahí que tome relevancia la alternativa temporal de gobierno propuesta en Torreón. Es decir, todo indica que las fuerzas revolucionarias no tenían prisa por organizar de inmediato los comicios federales; así que surge la interrogante de si la futura asamblea podía resolver

${ }^{21}$ Véase El Pacto de Torreón, en Contreras y Tamayo (1976, t. II, p. 98).

22 Véase Plan de Guadalupe, en Contreras y Tamayo (1976, t. II, p. 133).

\section{()(1) $(3$}


la competencia política con mecanismos de representación acordes a las circunstancias. Para ello se debe analizar la forma con que se propuso integrar la convención revolucionaria, pues el texto aceptado en los acuerdos expuso lo siguiente: "La Convención quedará integrada por delegados del Ejército Constitucionalista nombrados en junta de jefes militares, a razón de un delegado por cada mil hombres de tropa. Cada delegado a la Convención acreditará su carácter por medio de una credencial, que será visada por el jefe de la División respectiva". ${ }^{23}$

Estos requisitos acordados por los representantes de las divisiones del Norte y Noreste nos remiten a observar -en apariencia- dos de los mecanismos de una elección parlamentaria de la época: el primero de ellos se identifica cuando piden que cada delegado represente a mil hombres de tropa, pudiéndose entender con esto la formación de diputaciones; y el segundo se observa con la presentación de una credencial que acreditara a los representantes, situación sólo equiparada a los dispositivos de escrutinio electoral existentes en esos años para la Cámara de Diputados. Evidentemente, estos requerimientos no pueden equipararse con los existentes en una elección formal, ya que sólo serían nombrados los militares con rango de importancia. Por lo que el Primer Jefe bien pudo dar su consentimiento para la integración de la asamblea y así ganar tiempo en la preparación de una guerra contra la División del Norte (Ávila, 1991, p. 27); tan sólo recordemos que las fuerzas villistas se habían distanciado del constitucionalismo desde la toma de Zacatecas en junio de 1914.

\section{LA CONVENCIÓN REVOLUCIONARIA EN LA CIUDAD DE MÉXICO}

Mes y medio después de haber sido disueltos los poderes del régimen huertista, con los acuerdos de Teoloyucan, se iniciaron los trabajos preliminares de la Convención en la ciudad de México. Luis Fernando Amaya (1966) indica que para los militares no fue grata la presencia en ella de civiles, dado que Venustiano Carranza nunca especificó en los citatorios que los representantes de los generales, y de los gobernadores de los estados, debían ser del sector

${ }^{23}$ El Pacto de Torreón, en Contreras y Tamayo (1976, t. II, p. 98). Las cursivas son mías.

\section{(ㄷ)(1) $(3$}


castrense; así que los miembros de la Comisión de Pacificación ${ }^{24}$ se opusieron a que Luis Cabrera intentara organizar la elección de la mesa directiva. Es decir, cuando el abogado poblano les presentó una lista con los nombres de posibles candidatos a la presidencia de la Convención, los partidarios del elemento militar se mostraron "reacios a someterse a reglas y formulismos protocolarios" (pp. 75-77). Al final se optó nombrar al general Eulalio Gutiérrez como presidente de la mesa, y en las votaciones de los dos vicepresidentes, y de los cuatro secretarios, se eligió sólo a militares.

La primera discusión de credenciales - procedimiento ya acordado en Torreón y equiparado a cualquier escrutinio de integración del Congresoinició la tarde del 2 de octubre de 1914. El coronel Manuel García Vigil ${ }^{25}$ pidió la anulación de las representaciones del gobernador del estado de Oaxaca (licenciado Francisco Canseco) y su jefe de armas (licenciado Guillermo Meixueiro) "por ser de filiación netamente felicista". De estos dos personajes, quien más había apoyado al "sobrino del tío" era Meixueiro, aunque antes de ser derrotado Huerta, el inculpado había combatido al gobierno estatal de Oaxaca. ${ }^{26}$ Por esta razón los ataques se dirigieron hacia Canseco, y el coronel Samuel de los Santos ${ }^{27}$ le exigió que demostrara ser revolucionario. Rafael Buelna $^{28}$ fue más allá al denunciar que las insignias de muchos generales allí presentes "les habían costado cinco pesos" en una tienda de la capital,

${ }^{24}$ La comisión permanente de pacificación estuvo integrada por 49 militares. El objetivo de esta organización era procurar a toda costa el "entendimiento entre los grupos revolucionarios en pugna”. Sus voceros eran los generales Pesqueira, Buelna, Medina, Hay y Blanco (Amaya, 1966, p. 57).

${ }^{25}$ Oriundo de Oaxaca, simpatizó con el reyismo, pero como periodista apoyó a Madero. Después de 1913 se incorporó al constitucionalismo y tras ser delegado en la Convención fungió como diputado en el Constituyente y en algunas legislaturas posrevolucionarias. Cuando apoyó a Adolfo de la Huerta fue fusilado en 1924. Véase Así fue (1986, p. 1598).

${ }^{26}$ El oaxaqueño Meixueiro se enfrentó al constitucionalismo después de la Convención. Obtuvo una amnistía de Pablo González en 1919, pero quedó mal parado con los sonorenses y semanas después falleció. Véase, Asífue (1986, p. 1640).

${ }^{27}$ Constitucionalista potosino que representó a Jacinto V. Treviño en la Convención. En 1920 se adhirió al Plan de Agua Prieta y en 1923 apoyó al movimiento delahuertista. Cuando regresó a la política obtuvo un cargo en la Lotería Nacional y después fue jefe de división. Murió en la ciudad de México en 1956. Véase Así fue (1986, p. 1701).

${ }^{28}$ Sinaloense de buena posición socioeconómica, se levantó en armas desde 1910 y fue nombrado secretario de Gobierno del territorio de Tepic. Tras los sucesos de 1913 luchó contra Victoriano Huerta, pero al tener diferencias con Âlvaro Obregón se pasó al bando villista en 1915. Francisco Villa lo llamaba "mi muchachito", por su juventud, y Buelna siguió al Centauro del Norte hasta su derrota. Su última campaña militar la realizó en el movimiento delahuertista y en noviembre de 1924 fue asesinado en Michoacán a la edad de 33 años. Véase Asífue (1986, pp. 1554-1555).

\section{()(1) $\$$}


pues nadie los había visto antes en un campo de batalla (Amaya, 1966, p. 78), y por ello se pidió el nombramiento de una comisión -otra- que revisara "la autenticidad de los grados de los generales". Álvaro Obregón se opuso porque eso "era competencia del Primer Jefe y de la Secretaría de Guerra, no de la asamblea". ${ }^{29}$ No obstante, durante la sesión se buscó anular otras credenciales porque, "ante todo", debía "haber legalidad y no admitirse que haya chanchullos", como dijo Eduardo Hay. ${ }^{30}$

Luis Cabrera aseguró, por su parte, que detrás de algunas cédulas rechazadas yacía el criterio de "si sólo elementos militares" tenían "derecho a ser representantes en la Convención o también los elementos civiles". Amaya (1966, p. 79) indica que su intervención sólo buscaba evitar que los generales allí presentes se rebelaran contra el Primer Jefe, pues era evidente que conforme avanzaban los debates se cuestionaban más las invitaciones de Carranza. Así que el poblano los exhortó a "unificar la opinión". ${ }^{31}$ Álvaro Obregón decidió realizar entonces una junta privada, donde sólo tuvieron acceso los militares, y al día siguiente confirmaron su postura: la afinidad de criterios buscada por Cabrera sólo sería reconocida entre quienes formaban parte activa del Ejército Constitucionalista.

El 3 de octubre continuaron debatiendo las credenciales de los licenciados Canseco y Meixueiro. El coronel García Vigil insistió en que si no arrojaban a los felicistas de la asamblea, esta daría "albergue en su seno a la reacción”, y propuso el encarcelamiento para ese tipo de personas. Esta idea causó alboroto, porque los delegados oaxaqueños habían sido considerados precisamente por el Primer Jefe para asistir a la Convención. Y entonces se dio lectura a una propuesta de los generales Lucio Blanco, J. Gallegos y Salvador Herrejón; en ella rechazaban a "las personas que no" estuvieran "identificadas con la Revolución", "aun cuando" estas representasen a quie-

${ }^{29}$ Crónicas y debates de las sesiones de la Soberana Convención Revolucionaria (en adelante CDSCR) (1977), t. I, pp. 32-33, sesión del 2 de octubre de 1914.

${ }^{30}$ El ingeniero Hay fue uno de los primeros que tomaron las armas para apoyar el antirreeleccionismo de Madero; de hecho, el capitalino fue jefe del Estado Mayor del coahuilense en su campaña rebelde. Perteneció a la XXVI Legislatura y cuando Huerta dio el golpe militar, fue uno de los diputados que inmediatamente se lanzaron a la lucha contra el nuevo régimen. Desempeñó el cargo de secretario de Guerra y Marina en el gobierno preconstitucional de Venustiano Carranza. Después de ingresar a la XXVII Legislatura como representante, fungió como embajador en Italia. Y entre 1932 y 1933 fue director general de Aduanas. Años después, entre 1935 y 1940, fue secretario de Relaciones Exteriores. Véase Asífue (1986, p. 1611).

${ }^{31}$ CDSCR, t. I, pp. 34-35, sesión del 2 de octubre de 1914.

\section{(이요}


nes tuviesen "mandos de tropa". Eduardo Hay apoyó el documento porque todavía permanecía "fresca la sangre de nuestros hermanos derramada, en los campos de batalla, y ya los mismos causantes de que esa sangre generosa corriera a raudales, tratan de hacerse aparecer como revolucionarios de última hora". ${ }^{32}$

La efervescencia creada por la mencionada propuesta fue aprovechada por el general Hay; él preguntó cómo iban "a discutir los civiles [...] el criterio de los militares en cuya representación” venían, y respondió: "no podrán hacerlo. No podrán comprender los anhelos de los que padecieron hambre y sed y expusieron sus vidas en los campos de batalla." Poco a poco introdujo otra pregunta sobre quién había derrotado a Huerta, y aseguró que "los militares habrían triunfado sin la ayuda de los civiles". Debido a esto, Hay sostuvo que sólo al sector castrense debía "dejarse la resolución de los asuntos de la Patria" porque ellos eran "los únicos" que tenían "derecho a resolver lo que defendieron con su espada”.

Yo creo que es honrado y que no es indecoroso, por parte de los militares, exigir que se les reconozca el derecho de ser los únicos que implanten el nuevo gobierno, emanado de la Revolución sostenida por ellos. Y después de que los militares hayan llevado al terreno de los hechos los ideales de la Revolución, cuando los ideales por que pelearon bravamente estén resueltos, los civiles podrán venir a completar sin rencores y sin resentimientos. ${ }^{33}$

Las críticas de Hay fueron subiendo de tono; aseguró que "el enemigo de la Revolución" no era "la División del Norte", sino que este podía "esconderse bajo la ropa del civil que no ha sido luchador". Por ello continuó pidiendo la sumisión de quienes no habían tomado las armas, pues los civiles debían decirle a los militares: "tenéis razón; vosotros luchasteis en los campos de batalla, vosotros debéis resolver la situación que habéis creado”. Obregón intentó mesurar la postura del general argumentando que la expulsión de los civiles "constituía un crimen", ya que el senador Belisario Domínguez, pese a ser un civil, se había convertido en héroe. Pero Buelna lo interrumpió para asegurar "que la Convención tenía derecho de no admitir en su seno a los delegados que considere que no deben estar en ella”. El coronel De los Santos no estuvo de acuerdo con ellos, ya que "sólo el Primer Jefe del Ejército Constitu-

${ }^{32}$ CDSCR, t. I, pp. 36-37, sesión del 3 de octubre de 1914.

${ }^{33}$ CDSCR, t. I, pp. 37-38, sesión del 3 de octubre de 1914. Las cursivas son mías.

\section{()(1) $(3$}


cionalista tenía derecho para decir quiénes eran los autorizados para formar parte de la Convención”. Empero la propuesta de Blanco, Gallegos y Herrejón fue surtiendo efecto: García Vigil asentó que la asamblea no debía "acatar los mandatos de ninguna dictadura, porque era soberana en sus decisiones", y agregó, "de nada valdría estar reunidos a mañana y tarde [...] si los dictámenes se pasaban a la decisión del Primer Jefe, y este, de una plumada, borraba todo lo hecho". ${ }^{34}$

Luis Fernando Amaya (1966) opina que la postura de García Vigil era la correcta en los debates. La asamblea debía ser el órgano supremo de la revolución, con la suficiente autonomía y autoridad, para imponerse a los diferentes caudillos (pp. 81-82). Evidentemente, existen otras publicaciones donde se asienta que la convocatoria redactada en el Pacto de Torreón difería mucho del llamado hecho por Carranza para celebrar una asamblea en la ciudad de México, pues para Richard Roman (1976, p. 23), el Primer Jefe sólo buscaba la integración de una junta consultiva entre los generales constitucionalistas y así "encauzar y dirigir" sus trabajos.

Por esta circunstancia el caso del gobernador de Oaxaca era importante. La acusación de felicista fue tan nutrida hacia Canseco que el propio Luis Cabrera lo defendió señalando que por primera vez hablaría "en contra de sus convicciones de revolucionario". ${ }^{35}$ El argumento de mayor peso para el poblano era que el ejecutivo oaxaqueño había sido llamado por el Primer Jefe, de ahí que no podían rechazarlo. Pero ante la desaprobación de los militares, Cabrera cambió de estrategia; este les planteó que entonces le pidieran a Carranza el retiro del nombramiento hecho a Canseco. García Vigil preguntó de inmediato "iqué vamos a hacer si el Primer Jefe dice que no retira el llamamiento que hizo al gobernador de Oaxaca?" Y fue así como Obregón propuso el encarcelamiento de los inculpados; "el solo hecho de que permanezcan en este recinto", sostuvo, "constituye una amenaza muy seria, porque pueden corromper a los elementos sanos". Ante esa postura extrema, Cabrera les recordó a los asistentes la existencia de una "inviolabilidad de los delegados", pues dijo, "todos hemos sido llamados por el Primer Jefe para que desempeñemos muy altos deberes" y "debemos comenzar por respetar nuestra palabra de honor, si queremos que todos nos respeten". ${ }^{36}$ Eduardo Hay planteó entonces ofrecerle "toda clase de garantías" a los acusados, para

${ }^{34}$ CDSCR, t. I, p. 38, sesión del 3 de octubre de 1914.

${ }^{35}$ CDSCR, t. I, pp. 41-42, sesión del 3 de octubre de 1914.

${ }^{36}$ CDSCR, t. I, pp. 43-44, sesión del 3 de octubre de 1914.

\section{()(1) $\$$}


que no fueran recluidos al salir del recinto, y esto ocasionó que, al reanudarse la sesión por la noche, se aprobara por unanimidad un fuero para los integrantes de la Convención (Amaya, 1966, p. 83).

Uno de los momentos más significativos de las sesiones celebradas en la ciudad de México se dio la noche de ese 3 de octubre. Venustiano Carranza, en su carácter de Primer Jefe del Ejército Constitucionalista, se presentó a la Convención para exhortar a los asistentes a discutir "el programa político del Gobierno provisional de la República" y "los asuntos de interés general" que condujeran al país hacia "la realización de los ideales de justicia y de libertad". Las reformas más importantes de las que habló fueron "el aseguramiento de la libertad municipal", "la resolución del problema agrario" y el "mejoramiento de las condiciones económicas de la clase obrera"; ${ }^{37}$ aunque la parte medular del discurso vino cuando depositó su jefatura "en los generales y demás jefes que formaban la Convención” (lo que significaba su retiro). Cabe mencionar que Carranza pronunció estas palabras en voz baja, y "por eso los delegados no se dieron cuenta que el Primer Jefe [...] depositaba el poder en los generales y demás jefes que conformaban la Convención". ${ }^{38}$ Luis Cabrera aprovechó el momento y, después de asegurar que la revolución no había triunfado todavía, pues en la calle de Plateros (hoy Madero) se paseaban sus enemigos, propuso que no debían terminar la sesión "sin haber visto antes lo que" harían "con ese mando". El general Hay secundó al ex diputado de la XXVI Legislatura asegurando que aún no era "el momento de recibir ese gobierno y ese mando", y precisó que ellos ni siquiera se habían puesto de acuerdo en si debían permanecer o no "los elementos civiles o tan sólo los militares" en la asamblea. ${ }^{39}$

Amaya (1966) indica que Álvaro Obregón fue uno de los generales más sorprendidos por la delegación de facultades de Carranza en ese momento; días antes el sonorense le había enviado un telegrama al Primer Jefe para que "no entregara el poder a una junta predominantemente carrancista", sino a "la persona o personas que designara la Convención de Aguascalientes" (p. 86). Linda Hall (1995) señala que Obregón ya tenía intenciones de formar un grupo de caudillos revolucionarios que estuvieran dispuestos a dejar tanto a Villa como a Carranza, para establecer un gobierno dirigido por ellos. Por

${ }^{37}$ CDSCR, t. I, pp. 46-47, sesión del 3 de octubre de 1914.

${ }^{38}$ El periódico El Pueblo informó que las palabras de renuncia de Carranza "casi nadie pudo oírlas".

${ }^{39}$ CDSCR, t. I, pp. 50-51, sesión del 3 de octubre de 1914.

\section{()(1) $(3$}


lo que el rencor del sonorense no sólo se dirigía hacia el Centauro del Norte, quien estuvo a punto de asesinarlo en Chihuahua, sino también hacia el barón de Cuatrociénegas, quien había rechazado las medidas políticas que él y Villa le habían sugerido un mes antes. ${ }^{40}$

Ante este panorama, Cabrera se apresuró a decir "que no se trataba de aceptar ninguna renuncia, sino que el señor Carranza había hecho entrega del Poder a los jefes revolucionarios". En opinión del abogado, "lo único que restaba por hacer era la designación del nuevo Jefe del Ejército Constitucionalista y encargado del Poder Ejecutivo", por lo que de inmediato propuso la votación; "aquí está mi voto", dijo, "el primero, a favor de don Venustiano Carranza". ${ }^{41}$ Vito Alessio Robles ${ }^{42}$ (1980, pp. 106-107) describe esta intervención como un "hábil capotazo del licenciado Luis Cabrera", pues logró que el pleno rechazara la renuncia del coahuilense. Sin embargo, para Amaya (1966, p. 88) estas palabras tuvieron "escaso éxito, ya que la discusión continuó en el mismo tono y los oradores siguieron argumentando como si intencionalmente ignoraron las palabras del abogado poblano". Evidentemente, no es posible corroborar en los debates que de inmediato le hicieran caso a Cabrera, pero se debe valorar su intervención porque con ella no sólo logró dividir a los militares, sino también evitó que se manejaran nombres de posibles sucesores -tal y como lo quería Obregón-. Fue tan importante la maniobra de Cabrera que incluso un orador (del cual no se registró su nombre) argumentó que no podían aceptar la renuncia del Primer Jefe porque no estaban "representados" en la ciudad de México "todos los elementos de la Revolución" ${ }^{43}$

40 A finales de agosto de 1914, Villa y Obregón le pidieron al Primer Jefe que asumiera la presidencia interina y formara su gabinete para "dar término al estado extralegal de su gobierno". Además de esto, los gobernadores tendrían que convocar a elecciones de ayuntamientos, para que después se realizaran los comicios federales y estatales. Y a su vez el nuevo Congreso federal "elegiría a un civil como presidente y promulgaría leyes que protegerían a los pobres". Véase Hall (1995, pp. 68, 77).

${ }^{41}$ CDSCR, t. I, p. 53, sesión del 3 de octubre de 1914.

42 Oriundo de Saltillo, Coahuila, obtuvo el título de ingeniero en el Colegio Militar. En 1910 combatió a los maderistas en Chihuahua, siendo teniente coronel del Ejército Federal. Y a pesar de esto logró ocupar el cargo de agregado militar en Roma durante la presidencia de Francisco I. Madero. Al volver, en 1913, Huerta lo mandó a encarcelar y a raíz de esto se unió al constitucionalismo. Como delegado en la Convención apoyó las decisiones de la asamblea y fue nombrado gobernador del Distrito Federal durante la administración de Roque González Garza. Después de 1920 ocupó una diputación por el Distrito Federal, así como una curul de senador por Coahuila. Pero tras enfrenarse a Calles y Obregón por la reelección de este último, fue exiliado en Estados Unidos, donde se dedicó al análisis histórico. Murió en México en 1957. Véase Asífue (1986, p. 1537).

${ }^{43}$ CDSCR, t. I, p. 54, sesión del 3 de octubre de 1914.

\section{()(1) $\$$}


¿Ante qué escenario se encontraban los delegados constitucionalistas?, ¿la legitimidad de la Convención sólo se lograría al estar representados en ella los generales de la División del Norte y del Ejército Libertador del Sur?

Cumberland (1975, p. 148) asegura que la convocatoria del Primer Jefe para realizar una junta en la ciudad de México hizo "correr rumores en el sentido que la Convención estaría retacada con carrancistas que negarían" la participación de sus opositores. De acuerdo con este autor, el elemento que más apoyaba las sospechas era la invitación hecha por Carranza hacia los gobernadores nombrados por él. Aunque esta situación cambió vertiginosamente para el 4 de octubre: los jefes militares sostuvieron "abiertamente que sólo ellos tenían derecho de considerar y resolver los destinos de la República, haciendo abstracción completa de los elementos civiles a quienes consideran como peligrosos" ${ }^{44}$ Indudablemente, el sector castrense legitimaba de esa manera su participación exclusiva en la asamblea, por lo que Cabrera los interpeló con la pregunta de si sólo "los representantes de ciento cincuenta mil hombres armados" tenían "derecho de resolver los asuntos nacionales". En opinión de este célebre abogado, eso también debía "ocupar la atención de los que representan a catorce millones de habitantes". Y los generales pospusieron el debate para reunirse otra vez en privado.

Esa misma tarde, al reanudarse la sesión, se rechazaron tres credenciales, ${ }^{45}$ además de que se aceptaron seis sin discutir. Pero el momento culminante vino cuando Hay dio lectura a un documento en el que los generales Blanco, Obregón, Iturbe, Buelna y Medina (miembros de la llamada Comisión Pacificadora) ${ }^{46}$ invitaron "al Primer Jefe y a los miembros de la Convención para reunirse en Aguascalientes y seguir tratando allí la solución de los altos problemas nacionales". Después de esta exposición se adelantó que la minuta "no era susceptible de ser discutida", debido a que "sólo había que resolver si se aceptaba o no". Pero Samuel de los Santos les preguntó sobre quiénes "tenían derecho de acudir a esa Convención". El general Hay evadió la respuesta diciendo "que, para no perder el tiempo", primero firmasen la

${ }^{44}$ CDSCR, t. I, p. 58, sesión del 3 de octubre de 1914.

${ }^{45}$ Fue rechazada la credencial del militar Domingo Arenas por no estar "íntimamente" identificado con "la Revolución", y las de los coroneles Pedro Jarquín y Abraham Zepeda por no tener el grado de generales antes del 1 de octubre. CDSCR, t. I, pp. 59-60, sesión del 4 de octubre de 1914.

${ }^{46}$ Esta Comisión se formó por iniciativa de Lucio Blanco, quien no sólo fungía como líder de la facción más radical del constitucionalismo, sino que también era partidario de la negociación con el villismo y el zapatismo (Ávila, 1991, p. 93).

\section{()(1) $\$$}


invitación y "después se trataría acerca de los que tenían derecho de acudir a Aguascalientes". ${ }^{47}$ No obstante, De los Santos insistió en aclarar "1) Si ya había terminado la Convención que el Primer Jefe había convocado; 2) si la de Aguascalientes era una nueva Convención o continuación de la México", y "3) qué asuntos se iban a tratar allá" (Amaya, 1966, p. 92).

Ante este "cuestionario agresivo", advierte Amaya, Obregón aparentó gran serenidad para responder: la Convención de Aguascalientes sólo sería la continuación de la iniciada en México, aunque en la capital hidrocálida sí se reunirían los representantes de todo el Ejército Constitucionalista. El coronel David Berlanga ${ }^{48}$ pidió que entonces dijeran quiénes eran los que asistirían, debido a que el coahuilense Lucio Blanco ${ }^{49}$ y Eduardo Hay no eran claros en ello. Y Obregón respondió que sólo irían los generales. De inmediato Cabrera manifestó su inconformidad, ya que él mismo se encontraba trabajando para que "todos los elementos que fueron invitados para asistir a esta Convención” estuvieran en Aguascalientes. Mas ante los cuestionamientos de por qué se excluía a los civiles, el general Francisco $\operatorname{Coss}^{50}$ respondió: "cuando nos reuníamos los militares para atacar a los enemigos de la República, no

${ }^{47}$ CDSCR, t. I, p. 60, sesión del 4 de octubre de 1914.

${ }^{48}$ Profesor distinguido en Coahuila, estudió becado en Alemania y Francia durante el gobierno de Porfirio Díaz. En 1913 Berlanga se unió al constitucionalismo bajo las órdenes de Antonio I. Villarreal. Como delegado en la Convención votó por la renuncia del Primer Jefe, pero al oponerse a las directrices de Francisco Villa, este lo mandó fusilar. Así fue (1986, p. 1551).

${ }^{49}$ Lucio fue descendiente directo de Miguel Blanco, ministro de Guerra en el gobierno de Benito Juárez, por lo que se le considera de familia liberal. Ingresó a la revolución combatiendo al orozquismo y fue uno de los primeros en apoyar a Carranza, además de firmar el Plan de Guadalupe tras los sucesos de febrero de 1913. En Tamaulipas fraccionó una hacienda de Félix Díaz, dándose a conocer por ser el primero de los revolucionarios que realizó un reparto agrario; pero como esta decisión la tomó sin consultar al Primer Jefe, fue relegado por Carranza en la región. Durante la Convención abandonó el constitucionalismo y fungió como secretario de Gobernación en el gobierno de Eulalio Gutiérrez. Por su enemistad con Villa tuvo que abandonar el país, pero al regresar fue capturado y sólo Jesús Urueta pudo salvarlo del fusilamiento. Al sobrevenir el Plan de Agua Prieta salió de nuevo de México, aunque al regresar para vengar a Carranza, y combatir al obregonismo, fue asesinado en Tamaulipas en 1922. Asífue (1986, p. 1552).

${ }^{50}$ Minero coahuilense que militó en el Partido Liberal Mexicano, tomó las armas en 1906 y fue perseguido por el gobierno de Díaz. Después de un exilio en Estados Unidos se incorporó en 1910 al maderismo y para 1912 combatió a los orozquistas. En 1913 se unió a los constitucionalistas y durante la Convención permaneció fiel al Primer Jefe. En 1915 fue designado gobernador provisional de Puebla, aunque posteriormente se rebeló contra Carranza. Al apoyar a De la Huerta en 1923, y ser derrotado, huyó de nuevo del país. Regresó hasta 1942, para incorporarse al ejército, y murió en Coahuila en 1961. Ver Asífue (1986, p. 1570).

\section{()(1) $\$$}


tomábamos el parecer de los civiles". Obregón intervino entonces para explicar que ellos ya habían acordado con los jefes de la División del Norte que no asistirían los civiles. Y los reclamos de Cabrera volvieron al exigir "que los asuntos trascendentales del país" fuesen "tratados también por los civiles", al representar estos "a catorce millones de habitantes". ${ }^{51}$

De la intervención del ex diputado de la XXVI Legislatura fue desprendiéndose una problemática no abordada por la Comisión de Pacificación; este les advirtió que los civiles no serían eliminados de la División del Norte, ni del Ejército Libertador del Sur, por lo que instó a sus semejantes a abstenerse de asistir a la nueva Convención. Eduardo Hay intentó suavizar la disputa, asegurando que ellos habían ido "a la guerra precisamente" para que "los civiles no fuesen atropellados por los militares que no supieron ser soldados de la República”. Pero el coronel Berlanga secundó al poblano; es decir, como en el territorio hidrocálido no se iba a tratar "un problema militar, sino una cuestión social y, tal vez, el porvenir de nuestra Patria", eso no debía "ser tratado o resuelto por los militares". ${ }^{2}$

Este debate continuó hasta el día siguiente. Eduardo Hay arremetió contra Luis Cabrera para asegurar que los civiles de la Convención no representaban a 14000000 de habitantes, sino sólo a determinados generales y gobernadores. El fondo de la disputa parece más complicado, ya que Cabrera se había dispuesto lesionar la legitimidad política del sector castrense en la Convención al decir que ellos sólo representaban a 150000 hombres armados, una vez que los militares se mostraron reacios a permitir la participación en la capital aguascalentense de los civiles.

Cumberland (1975, p. 158) advierte que los más fervientes seguidores de Carranza en la Convención eran, precisamente, los civiles. Pero el 5 de octubre Cabrera manifestó que ellos cederían "toda labor y toda la responsabilidad" a los militares que continuaran los trabajos de la Convención en Aguascalientes. En opinión del abogado, claro está, no eran válidos los argumentos del sector castrense para arrebatarle a quienes no habían combatido "el indiscutible derecho de tomar parte en las cuestiones políticas del país". Y agregó:

Los militares que ya están picados de la araña [...] del militarismo, se convierten en autómatas si son subordinados o en absolutos dominadores cuando

${ }^{51}$ CDSCR, t. I, pp. 63-64, sesión del 4 de octubre de 1914.

${ }^{52}$ CDSCR, t. I, pp. 65-66, sesión del 4 de octubre de 1914.

\section{()(1) $\$$}


son jefes; y por consiguiente [...] toda intervención que hallan en el camino de su actividad [...] la interpretan inmediatamente como un estorbo a sus propósitos [...] Dentro del terreno de la acción el militar tiene razón, el civil estorba; en el terreno de la política no tiene razón; el civil ayuda. ${ }^{53}$

Luis Cabrera sostuvo que los civiles habían trabajado durante los combates de Sonora, Chihuahua y Coahuila para "facilitar la obra de los militares"; y era indudable que por ello debían ser escuchados. La ausencia del sector civil, "a la hora de las balas", no implicaba el abandono de responsabilidades y peligros, de acuerdo con el ex diputado. Así que recordó en la tribuna lo sucedido en el periodo maderista: "Durante el gobierno del señor Francisco I. Madero, los elementos militares más vigorosos con los que pudo contar, están vivos aún, están sanos, los elementos civiles fueron los sacrificados [...] En la presente lucha, los militares tienen siempre detrás de sí cinco, diez o veinte mil hombres que les sirven de garantía; los civiles no tienen detrás de sí esa protección" ${ }^{54}$

Tras estas palabras, el general Coss declaró que los militares ya habían "pactado de antemano" la ausencia del sector civil en los trabajos de la Convención; "sólo los que estamos muy bien empapados con el roce del soldado", aseguró, "hemos sentido las hambres y los fríos y levantado los heridos en los campos de batalla". Cabrera replicó que él no conocía "el sentir de los elementos militares", pero sí "el sentir de muchísimos desgraciados, muertos de hambre", que clamaban "por pan en la República" sin haber "tomado las armas". Ante estas discrepancias, el abogado aceptó que el sector menos numeroso y con "menor fuerza" cediera "el campo a los militares". Aunque antes de abandonar la tribuna, Cabrera les recordó que la patria no estaba "compuesta de civiles ni de militares", sino que a esa la conformaban todos. ${ }^{55}$

Era evidente que la retirada de los civiles de la Convención no podía posponerse más en la ciudad de México. La fuerza obtenida por la Comisión de Pacificación fue cada vez mayor en las sesiones y el propio Obregón mencionó que los revolucionarios tenían "más derecho de representar a los civiles que los mismos civiles". Es decir, para el sonorense "los catorce millones de habitantes de que nos habla el señor Cabrera" habían votado por "el señor Madero", pero "esos catorce millones de habitantes lo dejaron asesinar"; por

${ }^{53}$ CDSCR, t. I, pp. 71-72, sesión del 5 de octubre de 1914.

${ }^{54}$ CDSCR, t. I, p. 73, sesión del 5 de octubre de 1914. Las cursivas son mías.

${ }^{55}$ CDSCR, t. I, pp. 74-75, sesión del 5 de octubre de 1914.

\section{()(1) $\$$}


esa razón los "ciento cincuenta mil" hombres armados pretendían "devolver a esos catorce millones sus libertades" y "mejorar su condición social". ${ }^{56}$

Ávila (2014) considera esta disputa como la primera dentro del constitucionalismo, pues hasta entonces habían "marchado sin muchos contratiempos" bajo la dirección del Primer Jefe (p. 273). De tal manera que Cabrera rechazó la invitación de honor que le hicieron algunos generales para asistir a la capital hidrocálida. Esto no evitó que el abogado poblano escapase al descrédito de uno de sus principales oponentes, ya que en las crónicas aparece cómo Álvaro Obregón se burló de Cabrera cuando este dijo "que no necesitaba ser soldado para ser revolucionario, ya que tenía su pluma y con ella bastaba para batirse": la respuesta del sonorense fue "que había gallos de pico y de espolón”, porque él sabía de escritores que sabían batirse "en los campos de batalla", como "Cervantes, el autor del inmortal Don Quijote", y los que no enfrentaban "los peligros de los combates" -asentó- "sólo eran gallos de pico” (Alessio, 1980, p. 112).

\section{LA CONVENCIÓN REVOLUCIONARIA EN LA CIUDAD DE AGUASCALIENTES}

Uno de los trabajos que detalla la situación vivida en la capital hidrocálida, durante octubre de 1914, es el de Vito Alessio Robles (1980, p. 122); en él se narra cómo la pequeña ciudad albergó a millares de "soldados con cananas cruzadas en el pecho" y que la estación del ferrocarril no se daba abasto para acomodar todos los convoyes militares que a diario llegaban. Tanto él como Luis Fernando Amaya (1966, pp. 105-106) señalan que el ambiente respirado en la ciudad era de una gran feria, pues "su población fraternizaba con los soldados revolucionarios y recorría las calles de arriba abajo, bebiendo, cantando y disparando sus armas al aire en una liberación explosiva de inhibiciones atávicas". Sólo el traslado de las fuerzas villistas a Zacatecas provocó que los jefes asistentes tuvieran cautela, y la gente comenzó a decir que el número de escoltas y acompañantes de los generales "estaba en razón directa" al miedo que estos sentían por su vida.

La historiografía clásica de la Convención señala que en la capital aguascalentense se dieron cita tres bloques (todos ellos parte del constitucio-

${ }^{56}$ CDSCR, t. I, p. 80, sesión del 5 de octubre de 1914.

\section{()(1) $\$$}


nalismo cuando combatieron a Huerta). ${ }^{57}$ El primero de ellos era el villista, que se veía muy compacto; el segundo el carrancista, que ya venía dividido desde la ciudad de México, y el tercero era el independiente, que buscaba la unificación revolucionaria. Los carrancistas, pese a estar divididos, superaban en número a los villistas; que de 155 delegados, sólo tenían a 37 . No obstante, para algunos historiadores esa mayoría dentro de la asamblea sólo era formal; lo "que contaba realmente se encontraba afuera y estaba determinada por la relación de fuerzas entre los ejércitos” (Ávila, 1991, p. 105).

Cuando el 10 de octubre dieron inicio los trabajos preliminares de la Convención en el teatro Morelos, uno de los primeros delegados en intervenir fue el villista Felipe Dussart. Este le preguntó a la mesa directiva si la junta que iniciaba era una nueva, o si sólo fungiría como la continuación de la de México, a lo que los miembros del mencionado organismo respondieron que la de Aguascalientes "era la continuación de la única Convención Revolucionaria Mexicana" (Amaya, 1966, p. 107). De los autores que presentan un estudio pormenorizado de los debates, sólo Amaya advierte la participación del miembro de la División del Norte. Aunque la intervención de Dussart es de suma importancia para el presente estudio:

Permítame su señoría que en el curso de las discusiones de esta Convención no le llame a usted general, y que solamente le llame a usted y a todos los honorables de la mesa directiva, ciudadanos, porque en verdad somos ciudadanos armados, no somos el ejército que hemos vencido. Fuimos los patriotas que supimos agarrar un arma para ir a vengar la ofensa que se había lanzado contra la patria. ${ }^{58}$

Después de tan largos debates sobre la expulsión de los civiles en la ciudad de México, llama la atención que un revolucionario deje de lado su categoría para incluirse en el amplio espectro de la ciudadanía. Esta participación inaugurará una serie de discursos cargados de simbolismo, por lo inédito de la asamblea, así que al presentarse como "ciudadanos armados" o "patriotas", los revolucionarios se legitimaban y lograban distinguirse de los militares que habían estado bajo las órdenes de Victoriano Huerta (por eso

${ }^{57}$ Evidentemente, en esta clasificación no se toma en cuenta a los zapatistas que asistieron después de haberse conformado la Convención. De hecho, autores como Roman (1976, p. 32) advierten que los representantes del Ejército Libertador del Sur pidieron tener sólo voz, pero no voto, hasta que la asamblea tomara como ideario político el Plan de Ayala.

${ }^{58}$ CDSCR, t. I, p. 87, sesión del 10 de octubre de 1914. Las cursivas son mías.

\section{()(1) $(3$}


mismo se escucharon propuestas, como la de Murrieta, donde se pedía abolir toda distinción por ejércitos revolucionarios y considerarse "como una sola familia, para tratar los asuntos de gran interés para la patria"). ${ }^{59}$

Fue así como dieron inicio los trabajos de la Convención en la capital hidrocálida. Todo parecía estar dándose en un ambiente de cordialidad revolucionaria ${ }^{60}$ hasta que llegó el momento de integrar la comisión revisora de credenciales. Algunos delegados comenzaron a preguntar cuáles serían las bases y los criterios que dicho organismo utilizaría para realizar el escrutinio, por lo que Eduardo Hay planteó que sólo tuvieran cabida los generales cuyo grado estuviera reconocido por la asamblea. La razón principal para proponer esto, sostuvo el constitucionalista, era que él sólo tenía a un "asistente" a su "mando" (situación que podría dejarlo fuera de la Convención al pedirse que los delegados representaran a mil hombres de tropa). David Berlanga insistió en que el criterio inicial se sostenía para no llevar a la asamblea "la representación de un grado, sino la representación de un grupo de hombres", y este último representante propuso la toma de Zacatecas como fecha límite para fijar las incorporaciones del Ejército Constitucionalista, ya que en su opinión allí había tocado "a su fin" el movimiento revolucionario. ${ }^{61}$

Eugenio Aguirre Benavides ${ }^{62}$ apoyó a Berlanga en lo referente a que los jefes de armas representaran a 1000 hombres de tropa; si este criterio no se respetaba, sostuvo, podría darse la situación de "que en lugar de tener cien delegados, se nos presentarían mil". Las dudas respecto a los criterios de representación siguieron apareciendo y José Inocente Lugo ${ }^{63}$ preguntó si

${ }^{59}$ CDSCR, t. I, p. 90, sesión del 10 de octubre de 1914.

${ }^{60}$ Vito Alessio Robles (1980) narra cómo desde el 6 de octubre había llegado la mayoría de los delegados y que desde ese día el ambiente de cordialidad había imperado entre los asistentes. De hecho, cuando habla del banquete ofrecido por el general Martín Triana en la plaza de San Marcos, uno de los informantes del revolucionario le dijo "en todos los concurrentes se advirtió un gran anhelo de unión, paz, concordia y fraternidad. Los delegados enemigos de don Venustiano Carranza evitan hasta el nombrarlo y cuando se ven constreñidos a hacerlo lo efectúan con todo comedimiento y atención para no herir susceptibilidades" (pp. 122-123).

${ }^{61}$ CDSCR, t. I, pp. 95-97, sesión del 10 de octubre de 1914.

${ }^{62}$ Maderista de Coahuila que luchó contra la sublevación de Pascual Orozco. Tras la usurpación de Huerta se alió al constitucionalismo, pero tras la toma de Zacatecas de junio de 1914 firmó un documento donde se desconocían las órdenes de Carranza. Como villista tomó parte en la Convención de Aguascalientes y pidió la renuncia del coahuilense como Primer Jefe. Posteriormente fue subsecretario de Guerra en el gobierno de Eulalio Gutiérrez, pero tras ser capturado en Nuevo León lo fusilaron en junio de 1915. Véase Así fue (1986, p. 1534).

${ }_{63}$ Abogado guerrerense que se afilió al antirreeleccionismo en 1909. Fue gobernador de Guerrero entre diciembre de 1911 y abril de 1913, y después fue encarcelado por Huerta. Una vez libre se unió a las fuerzas de Gertrudis Sánchez y fue su delegado en la Soberana Con-

\section{()(1) $\$$}


los convencionistas podrían aceptar poderes de otras personas que tuviesen el derecho a asistir y no lo hicieren, pues con ello se generaría una multiplicación de votos por el número de individuos que pudiesen representar. Ante eso Berlanga reiteró lo conveniente de aceptar la propuesta del Pacto de Torreón, pues "aquel general que tuviera tres mil hombres" mandaría "tres delegados, y que aquel que tuviera siete mil hombres" enviaría "siete delegados, y no la voluntad de un grado". ${ }^{4}$

Respecto a la participación de los civiles, "allí se estipuló claramente que sólo serían admitidos como delegados los que hubieran luchado con las armas en la mano" (Alessio, 1980, p. 123). Pero los villistas propusieron un cambio a lo pactado en Torreón: que todos los generales, sin tomar en cuenta el número de hombres a sus órdenes, fuesen aceptados en la asamblea. Álvaro Obregón calificó esa nueva postura de la División del Norte como "justa y patriótica”. Aunque no advirtieron que, al aceptar esa reforma, los villistas podrían aumentar el número de sus representantes con los oficiales de José María Maytorena ${ }^{65}$ y sus aliados zapatistas (Amaya, pp. 109-110). La única restricción convenida en ese momento fue evitar que los delegados reuniesen en su persona a más de una representación.

Una vez pactadas las nuevas reglas, el 12 de octubre se reunieron los delegados en una segunda junta preliminar. El asunto que más los confron-

vención. Posteriormente se desempeñó como subsecretario de Gobernación en la presidencia provisional de Adolfo de la Huerta y fue gobernador de Baja California. A partir de 1932 tuvo los cargos de senador y general de brigada. Murió en 1963. Véase Asífue (1986, p. 1626).

${ }^{64}$ CDSCR, t. I, p. 108-111, sesión del 10 de octubre de 1914.

${ }^{65}$ Hijo de un acaudalado sonorense, José María estudió en California. Al regresar se hizo cargo de una de las haciendas más ricas de Guaymas y en 1909 apoyó la candidatura de Bernardo Reyes. Al fundar un club reyista en la mencionada ciudad, fue perseguido, por lo que al año siguiente apoyó al Partido Antirreeleccionista. Una vez firmados los acuerdos de Ciudad Juárez, fue electo gobernador del estado de Sonora y en 1912 combatió al movimiento orozquista. Su actitud tibia después de los sucesos de febrero de 1913 fue criticada, sobre todo porque no se opuso al gobierno de Huerta y dejó el cargo en manos de Ignacio Pesqueira. Durante su licencia como gobernador se fue a Estados Unidos para conferenciar con el secretario de Estado, William Bryan, el desconocimiento del régimen usurpador, y por esta situación el Primer Jefe le confió de nuevo la gubernatura de Sonora a partir de agosto de 1913. La tensión que tuvo con los obregonistas provocó que Plutarco Elías Calles lo acusara de intrigar contra Carranza y, aunque Maytorena se hizo cargo de nuevo del gobierno, Obregón lo desconoció. Por estos acontecimientos José María estuvo aliado con Villa en la Convención y reconocieron a Eulalio Gutiérrez como presidente provisional del país. En Sonora combatió a constitucionalistas como Calles y Benjamín Hill. Por órdenes de Villa entregó el gobierno estatal en octubre de 1915 y se marchó a California. Cuando años después intentó regresar al país, Calles lo expulsó; de ahí que sólo pudo terminar su exilio hasta 1938. Murió diez años después. Véase Asífue (1986, pp. 1638-1639).

\section{()(1) $\$$}


tó fue el mecanismo de discusión de credenciales, sobre todo, porque Hay propuso que únicamente aceptasen o rechazasen a los delegados con votaciones individuales de cada credencial. Cabe mencionar que dos días antes ya se había aceptado "como norma el reglamento de la Cámara de Diputados" (pues para algunos delegados -como José Lugo- ese estatuto era el que más se acercaba a "la naturaleza", a "la esencia", de la Convención). Sin embargo, Álvaro Obregón defendió la competencia de la comisión revisora para dictaminar si una credencial tenía "bien concedido el poder o no". Ante tales circunstancias, Villarreal aseguró tener "motivos para creer" que un representante de la lista recientemente aprobada por la comisión no era general, sino que había servido como jefe político durante la dictadura. Pero Roque González Garza ${ }^{66}$ defendió al organismo escrutador y sostuvo que la Comisión no tenía la culpa del nombramiento que el jefe superior del Cuerpo del Ejército había hecho para el caso de un militar de apellido Cordero. ${ }^{67}$

Uno de los momentos clave en la discusión de credenciales se dio cuando González Garza, representante personal de Villa, presionó al pleno para que validaran la cláusula donde "todos los generales con mando de fuerzas" tuviesen representación. En su opinión debían respetar el grado del general Zenón Cordero, ya que si ellos no lo consideraran "digno de pertenecer al ejército", sostuvo, eso era "completamente distinto" a la resolución del dictamen. Aguirre Benavides subió de tono la disputa al mencionar que

${ }^{66}$ Coahuilense que desde 1908 comenzó su oposición hacia Porfirio Díaz. Ferviente colaborador de Madero, lo acompañó en su gira presidencial y, de acuerdo con el Plan de San Luis, se levantó en armas en Chihuahua. Fungió como diputado renovador en la XXVI Legislatura y tras la Decena Trágica se incorporó a las fuerzas de Villa, distanciándose de Carranza. Fue representante del Centauro del Norte en la Convención. En enero de 1915 dicha asamblea lo nombró encargado del poder ejecutivo, en sustitución de Eulalio Gutiérrez. En junio de ese mismo año entregó el cargo a Francisco Lagos Cházaro y partió al norte para incorporarse a las tropas villistas. Al triunfo del constitucionalismo salió del país y sólo regresó tras el asesinato de Carranza. Fue diputado en la XXX Legislatura y murió en 1962, cuando tenía meses de haber sido nombrado por el presidente Adolfo López Mateos como coordinador de obras en Hidalgo. Asífue (1986, p. 1605).

${ }^{67}$ El único personaje que se encontró con este apellido y perfil fue el del poblano Zenón R. Cordero, quien había fundado una junta revolucionaria en los estados de Puebla y Tlaxcala. Tras los asesinatos de Madero y Pino Suárez fue encarcelado y posteriormente se unió al Ejército del Noreste, quedando bajo las órdenes de Pablo González. Tras firmar en abril de 1916 el Programa de Reformas Sociales y Políticas convencionista, tuvo que rendirse ese mismo año al constitucionalismo, cuando su general Domingo Arenas pactó con el gobierno ya constituido, y después pasó a formar parte de la diputación de Puebla en 1917. Para 1943 fue reconocido como veterano de la revolución y obtuvo la condecoración del Mérito Revolucionario. Véase Betancourt (2014, pp. 158-159).

\section{()(1) $(9$}


no podían aceptar que "un elemento enteramente reaccionario" ingresara a sus filas, aun cuando este tuviera "el grado de general", por lo que Eduardo Hay manifestó que Cordero era "un general identificado" en la división del Noreste y que sólo el Primer Jefe, y el general del Cuerpo del Ejército, podían removerlo. Cuando el debate se alargó, Hay sostuvo que el procedimiento a seguir por la asamblea debía consistir en pedir primero a esas autoridades que destituyeran a Zenón Cordero, pues se había acordado el ingreso de "todos los generales identificados". Aunque David Berlanga replicó: "para nosotros no hay Primera Jefatura; hay la Asamblea que está sobre el Primer Jefe, y esta Asamblea es Soberana; ante esta Asamblea deben responder los títulos y no ante el Primer Jefe" ${ }^{68}$ Eduardo Hay intentó calmar los ánimos, recordándoles que se había convenido con anterioridad la presencia de "los generales identificados o sus representantes". Pero Berlanga señaló:

La Asamblea ha procedido con toda consecuencia y con toda lógica y con todo derecho también. Con toda justicia no ha desechado del Ejército al general Cordero, lo ha desechado de aquí de la Asamblea. No es derecho de la Asamblea desechar del Ejército al general Cordero, eso será un asunto muy distinto; sí es derecho de la Asamblea aceptar o desechar a los que aquí vengan. ${ }^{69}$

El general Hay llamó al pleno a guiarse "por un espíritu de justicia", esta debía permanecer "sobre los sentimiento y sobre las simpatías". Gallegos corrigió al constitucionalista, debido a que en el texto final de la convocatoria se decía con claridad que la asistencia a la asamblea era para "todas las personas identificadas con la Revolución”. Por lo que la credencial de Cordero tuvo que ser desechada. Posteriormente se intentó que el recién expulsado fungiera como representante de otro general, pues sólo se pedía que los delegados fuesen del orden militar, a lo que Lugo manifestó que si el general Cordero no podía "ser representado, con mucha más razón" no podía "ser representante"; a él no se le identificaba "con el espíritu revolucionario" que animaba a "la asamblea". ${ }^{70}$

Ese mismo día, cuando fue reanudada la segunda junta preliminar, la discusión de credenciales continuó. Álvaro Obregón propuso desechar la credencial de Juan Neri, pues al no ser general ni gobernador, sino sólo teniente

${ }^{68}$ CDSCR, t. I, p. 124, sesión del 12 de octubre de 1914. Las cursivas son mías.

${ }^{69}$ CDSCR, t. I, p. 125, sesión del 12 de octubre de 1914. Las cursivas son mías.

${ }^{70}$ CDSCR, t. I, pp. 130-131, sesión del 12 de octubre de 1914.

\section{()(1) $\$$}


coronel, no tenía "ningún derecho" de permanecer en la asamblea. Pero Neri ya había asistido a la junta de la ciudad de México como invitado del Primer Jefe. Al respecto el secretario señaló haber tachado "los nombres de algunos individuos que no" debían "pertenecer a la Convención”, y Obregón objetó que en la lista apareciera el nombre de Luis Cabrera. Sobre este último señalamiento, el encargado de la mesa directiva respondió: "si son civiles, se considerarán borrados" ${ }^{71}$

Tras estas aclaraciones fue restablecida la discusión de credenciales y se abordó el caso del teniente coronel Cornejo. ${ }^{72}$ Este personaje fue señalado por el delegado Ortega como "servidor de la dictadura porfiriana". No obstante, el general Obregón lo defendió relatando pormenorizadamente cómo lo había conocido en Sonora y los peligros que el inculpado había sorteado bajo sus órdenes en la península de Baja California. El delegado Iturbe, pese a las declaraciones del connotado jefe del Ejército del Noroeste, se sumó a las desconfianzas sobre Miguel Cornejo, sobre todo por tener noticias de un pacto entre este y los federales. Pero el sonorense insistió en defender a su subalterno y pidió dejar de discutir su credencial para no "cometer un error": "en un día estará aquí el señor Cornejo, vendrá a contestar los cargos que se le hacen y entonces lo expulsaremos si no sabe defenderse". ${ }^{73}$ Después de estas declaraciones, Lugo apoyó la participación de Cornejo con el argumento de que su credencial se respaldaba por ser jefe político de la Baja California. Así que Obregón dijo desconocer si el inculpado había sido felicista o porfirista; en su sentir "siempre" había prestado "sus servicios a la revolución". Castillo Tapia indicó que los casos de Cordero y Cornejo eran idénticos y sostuvo: "si a este señor se le ha expulsado de aquí en la forma en que se hizo, no entiendo yo por qué no también al señor Cornejo". La diferencia entre esos casos, refutó Paniagua, era que nadie había defendido al general Cordero, "mientras que a favor del señor Cornejo el dignísimo señor general Obregón” estaba "alegando" por su representación. El representante personal de Villa -González Garza- propuso entonces la destitución de ambos, porque la culpa del

${ }^{71}$ CDSCR, t. I, pp. 133-134, sesión del 12 de octubre de 1914.

${ }^{72}$ Miguel Cornejo nació en el territorio de Baja California. Desde 1879 se había levantado en armas para combatir a la dictadura de Porfirio Díaz, así que llegado el año de 1913 aceptó la nominación de diputado suplente al Congreso, cargo que desempeñaba cuando fue disuelta la Cámara por Huerta. En 1914 se incorporó a las fuerzas de Álvaro Obregón y después ascendió a coronel de infantería. En la Soberana Convención estuvo representado por Francisco Serrano. Véase Betancourt (2014, p. 159).

${ }^{73}$ CDSCR, t. I, pp. 137-141, sesión del 12 de octubre de 1914.

\section{()(1) $\$$}


ingreso de Cornejo la tenían tanto la jefatura de la división de Cuerpo del Ejército del Noroeste, como el propio Obregón que lo había elevado al cargo. ${ }^{74}$

Ante la insistencia del general sonorense, la discusión sobre la credencial de Cornejo fue suspendida. El pleno decidió escrutar el resto de las cédulas, pero en los casos de las representaciones discutidas se culpó de nuevo a quienes les habían otorgado los grados de general a incipientes o dudosos revolucionarios. Obregón sugirió entonces que aceptaran sus credenciales, ya que estos delegados eran "bien pocos" y "no estorbarían para el resultado de la Convención". De ahí que "con una inconsecuencia que pasma, se aprobó la credencial expedida por el mismo Cornejo sin que este llegara a presentarse" (Alessio, 1980, p. 132). Ciertamente al llegar a este punto, Obregón habló de la necesidad de reforzar la comisión revisora de credenciales, "con cinco o seis elementos más del Ejército Constitucionalista”. No obstante, con las presiones del sonorense ya había ingresado un representante de quien varios revolucionarios dudaban.

Otro de los generales que provocó una controversia en la discusión de credenciales fue Pánfilo Natera García. ${ }^{75}$ Él ya había nombrado a un representante, pero pidió que este lo acompañase en la asamblea para discutir con mejor oratoria su postura. Ante esa duplicidad de curules, la Comisión le negó una credencial más. Aunque Berlanga no veía con malos ojos que ambas personas estuvieran juntas, en su caso sólo debían contabilizar un voto en lugar de dos. Mariel objetó, por su parte, el otorgamiento de dos credenciales a un mismo general, ya que eso podría propiciar que cada quien trajera a alguna personalidad, como el notable Luis Cabrera, y "toda distinción" era "odiosa". ${ }^{76}$

${ }^{74}$ CDSCR, t. I, pp.142-144, sesión del 12 de octubre de 1914.

${ }^{75}$ Campesino zacatecano que se unió al maderismo para lograr el reparto agrario en 1910. Dos años después defendió al presidente Madero del orozquismo, bajo las órdenes de Cándido Aguilar. Y en 1913 se levantó en armas con un grupo pequeño de rurales tras la Decena Trágica. Posteriormente tomó Torreón, junto con Villa, aunque Carranza le ordenó que fuera él quien dirigiera el asalto de Zacatecas, que sólo se logró con la participación del Centauro del Norte. Tras estos sucesos fue nombrado comandante general y gobernador provisional del estado de Zacatecas; con esa categoría asistió a la Convención en la ciudad de México y en Aguascalientes estuvo a cargo de la seguridad en esa capital, aliándose con las fuerzas de dicha asamblea. Para 1915 renunció a la gubernatura zacatecana, desconociendo a Villa, y un año después fue capturado. Como no le comprobaron los cargos imputados, quedó en libertad y reingresó al ejército. En 1923 defendió a Obregón del movimiento delahuertista y para 1925 fue nombrado jefe de Comisiones Inspectoras del Ejército. En 1937 fue ascendido a general de división y fue gobernador de nuevo de Zacatecas entre 1940 y 1944 , donde se destacó por su política agraria. Murió en 1951. Véase Asífue (1986, pp. 1653-1654).

${ }^{76}$ CDSCR, t. I, pp.149-150, sesión del 12 de octubre de 1914.

\section{()ㅜ(1) $\$$}


Al finalizar la segunda junta preliminar, el general Felipe Ángeles ${ }^{77}$ pidió a la asamblea que invitara a las tropas del gobernador José María Maytorena y al Ejército Libertador del Sur para formar parte en las sesiones (el mencionado representante habló de la importancia de incorporar a ese grupo de revolucionarios que se encontraban en rebeldía contra el Primer Jefe del Ejército Constitucionalista). Esa propuesta no era del agrado de Obregón y Hay, ya que desconocían cuántos delegados enviaría Zapata y sabían que "dentro del zapatismo había civiles que tenían el nombramiento de militares sin haber participado en acciones de armas" (Ávila, 1991, pp. 108-109). Mas Berlanga apoyó la propuesta; para él "los ideales" que perseguían "unos y otros" eran los mismos de quienes se encontraban en Aguascalientes: "vencer a la tiranía" ${ }^{78}$

El 14 de octubre de 1914, dos días después de estos debates, la asamblea se declaró soberana: a partir de esta fecha la Convención Revolucionaria se reconoció como la única institución de poder político y militar en México. El acto simbólico más importante se dio cuando los representantes pusieron su firma en una bandera nacional y juraron cumplir y hacer cumplir los acuerdos que de allí surgiesen. Después se designó a Eulalio Gutiérrez como presidente, rodeándolo de un gabinete; no obstante, esta situación no fue del agrado de los constitucionalistas y después cuestionaron la soberanía del organismo.

Del balance general de los trabajos de la Convención se advierte que ninguno de los grupos revolucionarios estuvo dispuesto a hacer concesiones

${ }^{77}$ Hidalguense que ingresó al Colegio Militar desde los catorce años. Destacado castrense de carrera, fungió como profesor en la institución que lo formó y en la Escuela Nacional Preparatoria. Ascendió a mayor después de estudiar en Estados Unidos y, tras mostrar su inconformidad por las injusticias del ejército con los yaquis y el favoritismo que imperaba en el Ejército Federal por las promociones, lo enviaron en una comisión a Francia. A principios de 1912 fue nombrado director del Colegio Militar por Madero y más tarde se trasladó a Morelos para sustituir a Juvencio Robles, quien combatía duramente al zapatismo. Durante la Decena Trágica viajó a la ciudad de México por petición del presidente, pero el coahuilense respetó la jerarquía militar y no lo puso al frente contra los rebeldes de La Ciudadela. Fue encarcelado después del golpe militar y, tras volver de un exilio obligado en octubre de 1913, se alió a las fuerzas de Carranza. Para 1914 se incorporó a la División del Norte como comandante de artillería y participó en las batallas de Torreón y Zacatecas. Representó a Villa en la Convención, de la que él mismo había sido promotor, y logró la incorporación del zapatismo a la asamblea. Ante el fracaso del gobierno convencionista, partió al noroeste con las tropas y abandonó a Villa cuando este no siguió sus recomendaciones. Se refugió en Estados Unidos después del triunfo del constitucionalismo y cuando regresó a México para reunificar a los villistas y derrocar a Carranza, fue capturado y fusilado en noviembre de 1919. Así fue (1986, p. 1541).

${ }^{78}$ CDSCR, t. I, pp. 160-161, sesión del 12 de octubre de 1914.

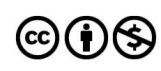


importantes respecto a la paz. La designación de Francisco Villa como jefe de armas del organismo acentuó las diferencias y fue así como las sesiones de la Convención se volvieron itinerantes (reuniéndose en la ciudad de México otra vez y en Cuernavaca, Toluca y Jojutla después). Hall (1995) sostiene que los implicados en esta asamblea siempre estuvieron conscientes que, al dominarla, obtendrían "un aura de legitimidad ante la nación mexicana" (p. 76). Aunque los vaivenes de la lucha armada pronto terminaron con los alcances políticos de esta asamblea.

\section{CONCLUSIÓN}

El presente artículo planteó la necesidad de estudiar las pugnas en torno a la legitimidad del periodo y concluye que el discurso sobre la representación política se radicalizó. Esto sucede, evidentemente, cuando el Ejército Federal sucumbe ante los ataques constitucionalistas y zapatistas; de ahí que al integrarse la Soberana Convención Revolucionaria se rechazó a los civiles en la reconstrucción de las instituciones políticas. Este trabajo muestra las etapas por las que transitó el discurso de las facciones en lucha y toma en cuenta el tránsito entre la "legalidad" de un gobierno golpista y la legitimidad que varios movimientos revolucionarios le infundieron a una asamblea.

Por ejemplo, en el primer apartado -donde se habló de los argumentos dados por la dictadura- encontramos a un sector de la prensa bastante comprometido con el régimen: el hecho de que cambiaran las versiones de los debates en la Cámara de Diputados, además de justificar veladamente las acciones de Victoriano Huerta, nos habla del gran interés que tenían estos medios por moldear a la opinión pública (aunque ese mismo gobierno asesinara a sus críticos y mantuviera un control totalitario de la administración). Los argumentos de esos diarios, cargados de un alto contenido religioso, reflejan el sentir de un sector hondamente conservador. Por lo que no es de extrañar que al arribo a la ciudad de México de las fuerzas constitucionalistas - primero- y convencionistas -después- se cerrasen El Imparcial y El Liberal, respectivamente, para usar sus instalaciones y editar nuevos diarios con diferente "signo político". 79

${ }^{79}$ Esta temática no pudo ser profundizada en el presente artículo, pero recomiendo el libro de Luciano Ramírez Hurtado (2010), capítulos III y IV.

\section{()ㅜ(1) $\$$}


Una vez entrados en el segundo apartado se observa un cambio radical en las formas de hacer política; la comisión de pacificación fue delineando una etapa militar con tintes parlamentarios para el país y uno de sus voceros fue Rafael Buelna, quien desde la ciudad de México inició los ataques contra los que no estaban "identificados con la Revolución". Por eso Luis Cabrera los cuestionó con el argumento de que 150000 hombres armados no podían representar a 14000000 de habitantes; aunque Eduardo Hay se encargó de refutar al abogado recordándole que los civiles sólo representaban en la capital a determinados gobernadores o generales. De esa manera, al trasladarse la Convención a Aguascalientes, quedó de manifiesto que muchos revolucionarios no tenían intención de obedecer al Primer Jefe - un civil- en el nuevo órgano político.

Al ser esta una etapa de inestabilidad y efervescencia, la Soberana Convención Revolucionaria sobresale en el contexto de la legitimidad política del periodo: sus integrantes debatieron las propuestas de constituir un órgano deliberativo de gobierno, precisamente cuando el vacío de poder hacía patente un alto en la lucha armada. En este trabajo se aprecia que fue en la ciudad de México donde más se definieron los criterios de representación para dicha asamblea, aunque esas propuestas pronto cedieron su viabilidad ante los intereses políticos y militares mostrados en la capital hidrocálida.

Cabe mencionar que la idea inicial de la convocatoria, sobre que asistiera un representante por cada 1000 hombres de tropa, pudo haber dado a los revolucionarios un inédito órgano de gobierno. Desgraciadamente, los grupos armados menos numerosos advirtieron que no podían competir políticamente con esas reglas y sus presiones provocaron que sólo se les diera representación a los generales de los diferentes ejércitos revolucionarios (teniendo más peso la organización militar que una institucional y representativa). Una vez reunido este sector castrense en Aguascalientes, se olvidaron del anhelo de unidad profesado por aquellos "patriotas". De ahí que la autoridad de la Convención pronto vio mermada su legitimidad (fortaleciéndose de esa manera el llamado gobierno preconstitucional de Venustiano Carranza en Veracruz).

Mucho se ha hablado sobre las expectativas que generó esta asamblea, sobre todo cuando sesionó en Aguascalientes; pero poco se reflexiona en torno a las propuestas emergidas posteriormente de ella: el que la Soberana Convención instaurara el parlamentarismo en México, por ejemplo, tenía que ver con una "crítica devastadora que la Revolución había hecho de las instituciones de la dictadura”, como asentó Arnaldo Córdova (1990, p. 132).

\section{()(1) $(9$}


Esa crisis de legitimidad se convirtió, como hemos visto, en una oportunidad para cuestionar la representación en el nuevo órgano político.

Para finalizar, mencionaré que la crítica de Álvaro Obregón hacia Luis Cabrera, sobre "que había gallos de pico y de espolón" (porque muchos políticos no enfrentaban "los peligros de los combates"), refleja desdén hacia un sector que había participado de una u otra manera en la revolución. Excluir a los civiles como candidatos, en años posteriores, evidenciará que sólo los revolucionarios armados, "como una sola familia", tendrían el derecho de gobernar; lo que sin duda representó un retroceso a la democracia practicada durante el gobierno de Francisco I. Madero.

\section{LISTA DE REFERENCIAS}

Alessio Robles, V. (1980). La Convención Revolucionaria de Aguascalientes. México: Biblioteca del INEHRM.

Amaya, L. F. (1966). La Soberana Convención Revolucionaria, 1914-1916. México: Editorial Trillas.

Así fue la Revolución mexicana. Los protagonistas (1986). México: SEP/Comisión Nacional para las Celebraciones del 175 Aniversario de la Independencia Nacional y 75 Aniversario de la Revolución Mexicana.

Ávila Espinoza, F. A. (1991). El pensamiento económico, político y social de la Convención de Aguascalientes. México: INEHrm.

Ávila Espinoza, F. A. (2014). Las corrientes revolucionarias y la Soberana Convención. México: El Colegio de México/IneHrm/Universidad Autónoma de Aguascalientes.

Betancourt, C. (comp.) (2014). Los hombres de la Soberana Convención Revolucionaria. México: SEP/INEHRM/UAA.

Cabrera, L. (1948). Sufragio efectivo. No reelección. En A. Pani (comp.), Una encuesta sobre la cuestión democrática en México. México: Editorial Cvltvra.

Contreras, M. y Tamayo, J. (1976). México en el siglo xx. 1913-1920. Textos y documentos. (t. II). México: unam.

Córdova, A. (1990). La herencia de la Soberana Convención Revolucionaria. En La Soberana Convención Revolucionaria en Aguascalientes, 1914-1989. Aguascalientes: Gobierno del Estado de Aguascalientes.

Crónicas y debates de las sesiones de la Soberana Convención Revolucionaria [Introd. y notas de F. Barrera Fuentes]. (1977). (t. I). México: Biblioteca del INEHrm.

Cumberland, Ch. (1975). La revolución mexicana. Los años constitucionalistas. México: Fondo de Cultura Económica.

\section{()(1) $\$$}


De cómo vino Huerta, y cómo se fue... Apuntes para la historia de un régimen militar (1978). [ed. facsimilar de 1914]. México: Ediciones El Caballito.

Diario de los debates de la Cámara de Diputados. Segunda XXVI Legislatura, año II, periodo I, t. III (1913). México: Imprenta de la Cámara de Diputados.

Diego Romero, J. de (2003). Revolución y legitimidad política en la América Latina contemporánea. Los casos de Cuba y Nicaragua. Revista Complutense de Historia de América, 29.

Hall, L. (1995). Álvaro Obregón. Poder y revolución en México, 1911-1920. México: SEdenA.

Historia sumaria del Poder Legislativo en México. (1997) (vol. I, t. 1, serie I de la Enciclopedia Parlamentaria de México). México: Cámara de Diputados del Congreso de la Unión/Miguel Ángel Porrúa.

Levi, L. (1997). Legitimidad. En N. Bobbio, N. Matteucci y G. Pasquino, Diccionario de política. México: Siglo XXI.

Mac Gregor, J. (enero-abril, 1986). La XXVI Legislatura frente a Victoriano Huerta. ¿Un caso de parlamentarismo?, Secuencia, 4. DoI: http://dx.doi.org/10.18234/secuencia.v0i04.122

Mac Gregor, J. (2010). Belisario Domínguez. Moral y ética, impronta de vida. México: Lectorum.

Mac Gregor, J. (2015). La XXVI Legislatura. Un episodio en la historia legislativa de México. México: El Colegio de México.

Mac Gregor, J. (2017). Los diputados renovadores. De la XXVI Legislatura al Congreso Constituyente. Historia Mexicana, 66(3). Recuperado de http://historiamexicana.colmex.mx/index.php/RHM/article/view/3382

Meyer, E. (1990). El oficio de recordar, memoria silente de la Soberana Convención. En La Soberana Convención Revolucionaria en Aguascalientes, 1914-1989. Aguascalientes: Gobierno del Estado de Aguascalientes.

Portillo Valdés, J. (2016). Historia mínima del constitucionalismo en América Latina. México: El Colegio de México.

Quirk, R. (1962). La revolución mexicana 1914-1915. La Convención de Aguascalientes. México: Editorial Azteca.

Ramírez Hurtado, L. (2004). Aguascalientes en la encrucijada de la revolución mexicana. David Berlanga y la Soberana Convención. Aguascalientes: UAA.

Ramírez Hurtado, L. (2010). Imágenes del olvido 1914-1994. Discurso visual, manipulación y conmemoraciones de la Soberana Convención de Aguascalientes. Aguascalientes: UAA.

Ramírez Rancaño, M. (julio-diciembre, 2005). La república castrense de Victoriano Huerta. Estudios de Historia Moderna y Contemporánea de México, 30.

\section{()(1) $(2$}


Rojas, R. (2002). La oposición parlamentaria al gobierno de Francisco I. Madero. En I. Marván y M. A. Casar (coords.), Gobernar sin mayoría. México 1867-1997. México: Taurus/CIDE.

Roman, R. (1976). Ideología y clase en la revolución mexicana. La Convención y el Congreso Constituyente. México: SepSetentas.

Romero Flores, J. (1998). Los crímenes de Victoriano Huerta. En E. de la Torre Villar (comp.), Lecturas históricas mexicanas (t. III). México: UNAM.

Rosanvallon, P. (1999). La consagración del ciudadano. Historia del sufragio universal en Francia. México: Instituto Mora.

Rosanvallon, P. (2010). La legitimidad democrática. Imparcialidad, reflexividad y proximidad. Madrid: Paidós.

Sayeg Helú, J. (1982). La revolución mexicana a través de sus documentos fundamentales (1913-1916). México: Biblioteca del InEHrm.

Schmitt, C. (1981). Teoría de la Constitución. México: Editorial Nacional.

Schmitt, C. (2012). Posiciones ante el derecho. Madrid: Editorial Tecnos.

Tena Ramírez, F. (1976). Derecho constitucional mexicano. México: Editorial Porrúa. Tilly, Ch. (1995). Las revoluciones europeas, 1492-1992. Barcelona: Editorial Crítica.

Ulloa, B. (1976). La revolución intervenida. Relaciones diplomáticas entre México y Estados Unidos (1910-1914). México: El Colegio de México.

\section{OTRAS FUENTES}

\section{Hemerografía}

El Diario. Diario Independiente de la Mañana.

El Imparcial. Diario Independiente. 